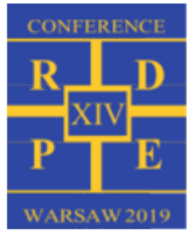

\title{
Preheating procedure for fast start-up of a steam turbine from a cold state
}

\author{
Wojciech Kosman ${ }^{1,}{ }^{*}$, Andrzej Rusin ${ }^{2}$ \\ ${ }^{1}$ Silesian U niversity of Technology, ul. K onarskiego 18, Gliwice, wojciech.kosman@ polsl.pl, Poland \\ 2 Silesian University of Technology, ul. K onarskiego 18, Gliwice, andrzej.rusin@ polsl.pl, Poland
}

\begin{abstract}
The paper describes a procedure that allows to start up a steam turbine in a significantly shorter period. The procedure is developed for start-ups that begin from a cold state, when the temperature of the parts of the turbine is close to the ambient temperature. The pre-heating rises the parts temperature before the actual start-up begins. It changes the thermal state of the turbine and causes smaller maximal stress during the initial period of the start-up. The procedure involves a pre-heating of the turbine with a hot air generated in an electric heater. The paper describes the requirements of the process. It presents the possible configurations of the flow in the turbine and the analysis of the thermal and the strength state of the turbine during the pre-heating.
\end{abstract}

\section{Introduction}

During the changes in the structure of the power generating industry in the recent years steam cycles survived as the core systems [1-3]. However their operation has changed considerably [4]. It is now affected by the operation of the renewable energy sources including solar and wind power [5]. The power generation based on these sources is not constant. They depend largely on the ambient conditions. The core systems, including the steam cycles, compensate the changes in the load of the renewable sources [6]. The operational conditions of steam turbines change much more frequently.

The conditions that undergo frequent changes result in an intensive fatigue process in steam turbines $[7,8]$. The number of start-ups is larger than ten or twenty years ago. In many cases it exceeds 50 start-ups per year. A lso the load ramps happen very often.

The negative effects of the fatigue process may be reduced if the change of the stresses in the machines occurs at slower rate and with a lower amplitude. In steam turbines this may be achieved if the temperature of the working fluid changes in an appropriate way.

The larges amplitudes of the stress occur in steam turbines during start-ups from a cold state, when the initial temperature of the machines is equal to the ambient temperature. The start-up from these conditions is al so the longest one.

The aim of the research presented here is to shorten the start-up period of a steam cycle while maintaining a safe level of stresses. The suggested procedure is a rearranged version of the original sequence designed by the manufacturer. The turbine and the boiler begin their start-up procedures at the same time as opposed to the sequential order. The process is presented for the 13K 215 steam turbines type.

\section{Modification of the start-up procedure}

A typical start-up procedure of a steam cycle includes three basic steps. They are shown schematically in the fig. 1a and listed below.

1. B oiler start-up.

2. Heating of the steam pipes.

3. Turbine start-up.

This sequence depends on the availability of the steam. At the end of the first step the boiler already generates steam, although its temperature and pressure are much lower than the design, full load values.
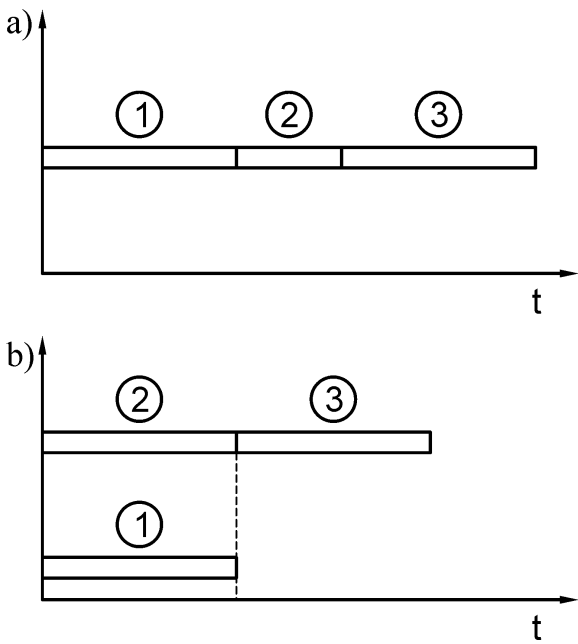

Fig. 1. Turbine start-up sequence: original (a), with a pre-heating (b) 
The steam is then used to heat the pipes between the boiler and the turbine. In some turbines a small fraction of the steam is delivered into the space between the inner and the outer casing in the high pressure and the intermediate pressure sections of the turbine in order to heat up the casings and the rotor. Even though the rotor is not directly exposed to the steam at this point, it is running to avoid its deformation. The larger fraction of the steam bypasses the turbine through the pressure reduction valve and the cooling system.

In the start-up sequence described above the heating of the pipes and the turbine may not begin before the boiler starts to deliver the steam in the required amount.

The approach towards the optimization of the start-up begins with the observation that the heat source for the heating of the pipes and the turbine does not have to be the steam generated in the boiler. If the heat may be delivered from another source then the start-up sequence may be rearranged.

The suggested sequence of the start-up is shown in fig. 1b. The heating of the turbine may start at the same time, when the boiler begins its operation. This step is now called a pre-heating to distinguish it from the heating with the steam from the boiler. The whole period of the start-up becomes much shorter.

In the optimized procedure the heating of the turbine from an external source is independent of the available steam temperature from the boiler. It means that the heating process itself may be optimized. The key idea is to raise the temperature of the turbine during the preheating to such a level that allows the admission of the steam from the boiler at high temperature. If this is achieved then the cold start-up becomes similar to a start-up from a warm state, when the period between a preceding shut-down and the start-up is less than 50 hours. The whole start-up becomes even shorter. This is explained in fig. 2. The figure shows the change of the live steam temperature during a start-up. The dashed line is a manufacturer's curve and the solid line corresponds to the optimized procedure.

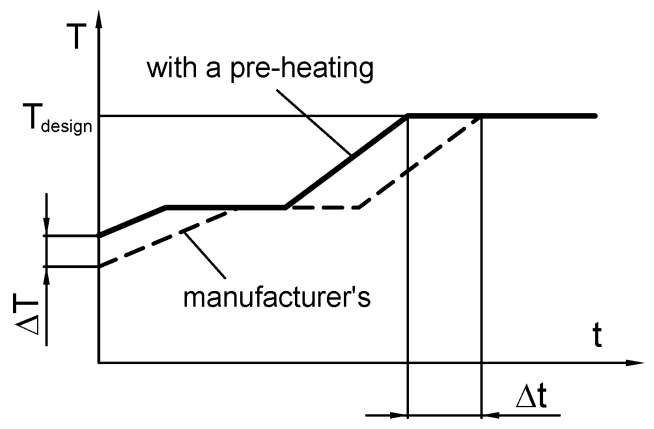

Fig. 2. Start-up temperature curves

If the turbine is pre-heated then the live steam temperature may be higher in the moment when the cutoff valves open and the live steam starts to flow into the turbine. Hence the temperature difference $\Delta T$ in the fig. 2. The result is the time difference $\Delta t$, which means that the design value of the live steam temperature is reached earlier than in the manufacturer's start-up. This effect occurs even without any other optimization. The rate of the increase of the temperature is the same for the manufacturer's curve and for the optimized one - the slopes of the lines in the fig. 2 are exactly the same.

\section{Heat source options}

A very important issue is the choice of the external heat source for the pre-heating. There are several possible options described below.

\section{a) Steam from an external source}

The turbine parts may be exposed to the steam from a different turbine in the same power plant. The pressure and the temperature of the steam may be adjusted to the required levels through the throttling and the water injection.

M ost power plants have several steam turbines and at least one is al ways running. It means that there is al ways steam available for the pre-heating.

The usage of the steam from an external source is related to several issues that make the pre-heating process problematic. First of all the pre-heating system involves two power generating units. One delivers the heat and the other receives it. This means that the two cycles must be adapted to both: the delivery and the reception of the heat. The application would involve the modifications of the cycles in two separate points each.

Secondly the heat delivery system would have to include at least one steam extraction. The temperature of steam for the heating must be relatively high (250 $400^{\circ} \mathrm{C}$ ). This excludes a common pipe that is usually fed from each turbine in a power plant because of the low temperature.

There are also operational issues. The steam parameters in an extraction strongly depend on the load in the turbine. In order to provide stable steam parameters for the pre-heating, the turbine that delivers the heat would have to maintain stable load for the period of the pre-heating.

Further the problem of the steam condensation must be taken into the account. The heating steam would be delivered in small streams to a cold turbine. This would result in some amount of the water gathering in the lower areas of the turbine and the water would have to be removed through the drainage system. The condensation influences the temperature of the parts exposed to the steam and makes the process more difficult to control.

\section{b) Electric heating mats}

A relatively fast temperature increase may be achieved if turbine parts are covered with electric mats. The pre-heating process may be conducted without any hot fluid.

Unfortunately the choice of the locations in turbines where the mats may be installed is very restricted. The only place inside a turbine is the external surface of the inner casing. The rotor would then be heated indirectly through the inner casing. Also the mats located in the area between the inner and the outer casings would be exposed to the leakage steam that creates erosion conditions. 


\section{c) Hot air}

The use of the hot air eliminates the problems caused by the two previously described methods. The air flow may be arranged just like the steam flow. At the same time the problem of the steam condensation and the necessity of the water removal is significantly reduced. The air may be used to the direct heating of the casings and the rotor.

The hot air pre-heating is considered in the further analysis. The pre-heating system consists of an electric air heater and the compressor that provides a pressure level required to overcome the pressure losses in the pipes and the turbine. The process may be easily controlled. The two main parameters that are adjusted is the amount of the air and its temperature. The heating conditions may be matched to the requirements that depend on the thermal state of the turbine parts.

\section{Existing thermal systems}

The 13K 215 turbines have two systems that affect the thermal state of the machine parts. The first one is used during a forced cooling of the turbine after the shutdown of the power generating unit. The system allows to decrease the temperature of the metal of the turbine parts and begin the maintenance works in a much shorter period when compared to natural cooling. A simplified diagram of the system is shown in fig. 3.

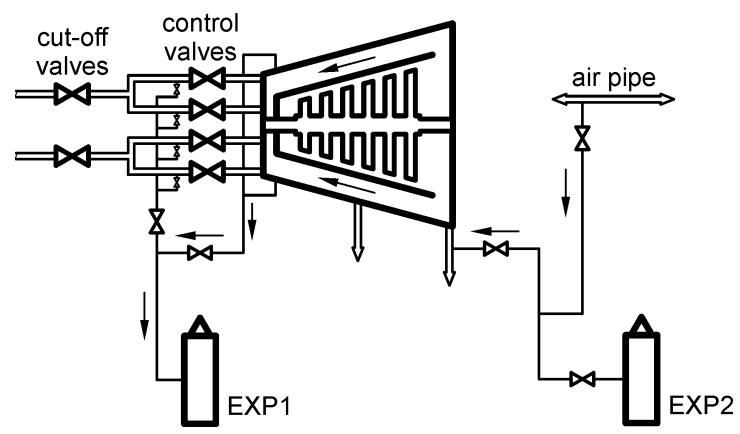

Fig. 3. Forced cooling system

After the control valves are closed the compressed clean air is delivered from the air pipe. The air flows through the expander EXP2, which under normal operation is a part of the drainage system. The cooling air flows from the outlet of the turbine to the inlet - the flow is opposed to the steam flow. The air leaves the turbine through the pipes connected to the expander EXP1 that is also a part of the drainage system. The system does not include a separate compressor because the air pressure in the delivery pipe is high enough to force the flow.

Due to the closed position of the control valves the air does not flow through the blades path but into the area between the inner and the outer casing. The rotor is cooled indirectly and the heat from this part is rejected through the inner casing. This arrangement of the flow is necessary to prevent the damage. In this particular turbine the rotor is of a disc type and the discs act as fins that intensify the heat transfer. Therefore if the rotor was exposed directly to the cooling fluid during the forced cooling it would shrink faster than the casing. In the result the rotating blades on the rotor could come into the contact with the stationary nozzle blades and cause damage.

The second system that affects the thermal state of the turbine is the heating system for the casings. As mentioned before the exposure of the rotor to a fast flowing fluid results in a rapid increase of the metal temperature. During a start-up when the rotor is exposed to hot steam the relative elongations between the rotor and the casings may become very large. This may occur especially during a start-up from a cold-state.

In order to prevent large relative elongations a small fraction of the steam is delivered to the area between the inner and the outer casings. This intensifies the heating of the casings and allows to keep the relative elongations between the rotor and the casings in a safe range. This small, additional flow is shown in the fig. 4.

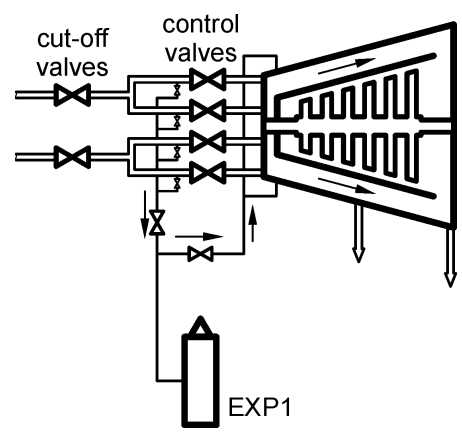

Fig. 4. Casings heating system

The steam is taken from the main live steam pipe from small extractions located in front of the control valves. The extracted steam flows through the pipes that are a part of the drainage system and is delivered into the front area of the turbine. The casings heating system uses the same pipes as the forced cooling system.

The casing heating system may operate during any phase of a start-up. The only restriction is the steam temperature. If it exceeds 86 percent of the design value of the live steam temperature the system must be cut off. U sually the operation of the system is determined on-line on the basis of the measurements of the casings temperature and the relative elongations between the casings and the rotor.

The pre-heating system may use the parts of both systems described above. Since the systems are able to handle flows of the temperature up to about $86 \%$ of the design live steam temperature there is no danger of overheating the pipes. Also no modifications to the existing turbines are required, so the suggested system may be applied to older machines as well.

\section{Air flow}

The rate of the heat transfer depends on the following three issues related to the flow of the hot air:

- temperature,

- mass flow rate,

- flow arrangement. 
In the proposed design the temperature of the air and its flow rate are to be controlled during the process. The flow rate is adjusted either by the valves or by matching operation of the compressor to the required amount of the air. The temperature may be controlled through the electric power for the coils in the air heater.

The base values for the flow rate and the temperature are determined in the following way. The mass flow rate may be chosen equal to the flow during the forced cooling after the power unit shut-down. This ensures that the amount of the air is correct for the particular size of the turbine. The maximal temperature of the air is restricted by the value given in the description of the casings heating system in the previous section. For the sake of safety the maximal air temperature should be set at an even lower level. In the calculations presented in this paper the maximal air temperature was either 350 or $400^{\circ} \mathrm{C}$. It should be noted here that the pre-heating is not meant to substitute the heating with the steam from the boiler. Its task is simply to shorten the period of turbine start-up.

The air pressure should be high enough to force the flow through the turbine.

The key feature is the arrangement of the air flow in the turbine. Figure 5 shows the basic designs. a)

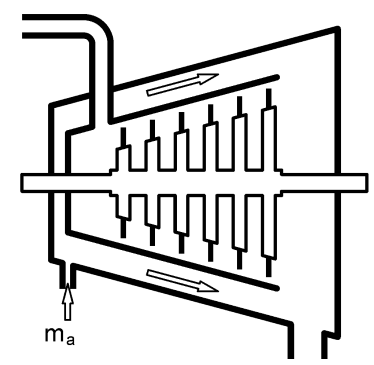

b)

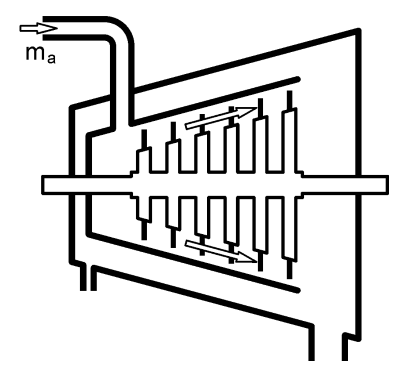

Fig. 5. Basic air flow in the turbine

In the design presented in the fig. 5a the air flows in the same direction as the steam in the casing heating system (see the previous section). The steam enters the area between the inner and the outer casings. It flows towards the rear end of the turbine. The temperature of the inner and the outer casings is increased first and then the temperature of the rotor.

The design from the fig. $5 b$ assumes the same direction of the flow as during the operation of the turbine. The air enters the nozzle box and then flows through the blades path from the inlet to the outlet. Due to the low pressure of the flow the expansion process is negligible. The air must overcome the pressure losses related to the flow through ducts.

In this arrangement of the flow the rotor is heated directly while the outer casing is heated indirectly. According to the notes given in the preceding sections this related to the most intensive heat transfer process on the surface of the rotor. The relative elongations between the rotor and the casings may change very fast. However in contrast to the cooling process where turbine parts shrink the thermal expansion here does not lead to a direct contact between the stationary and the rotating parts of the turbine. This is due to the clearances that are larger between a rotor blade and the following nozzle blade than between the rotor and the preceding nozzle. Also the air heating may easily be controlled - easier than heating with steam.

Nevertheless the design from the fig $5 b$ is treated here only as a reference to determine the limiting parameters of the air.

Figures 6 and 7 present additional cases of the air flow through the turbine. The case from the figure $6 a$ is used in some turbines during the forced cooling after the shut-down of the steam cycle. The air enters the area between the casings and flows towards the rear end of the turbine. The valves at the outlet pipes are closed and the air cannot leave the turbine there. The air flows towards the front of the turbine through the blades path and exits through the nozzle box and live steam pipes. This arrangement exposes all three of the main parts of the turbine to the air: the rotor and both casings. a)

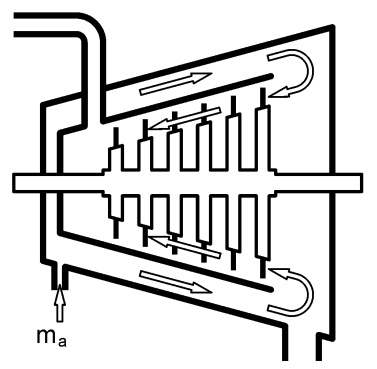

b)

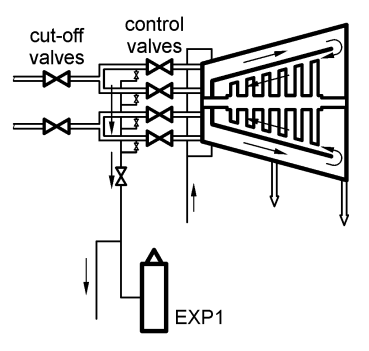

Fig. 6. Pre-heating with a reversed air flow

The application of the case from the fig. 6 a requires small modifications in the drainage system of the turbine. The entry and exit locations of the air must be modified according to the fig. $6 \mathrm{~b}$.

The flow arrangement from the fig. 6 has one major disadvantage: the heating of the rotor and the casings is al ways conducted proportionally. If the heat transfer rate is increased for the casings then the proportional increase occurs for the rotor. That is why yet another designed is considered. It is shown in the fig. 7. a)

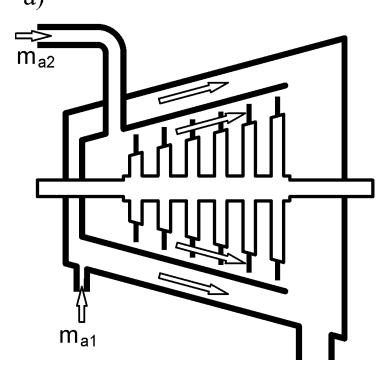

b)

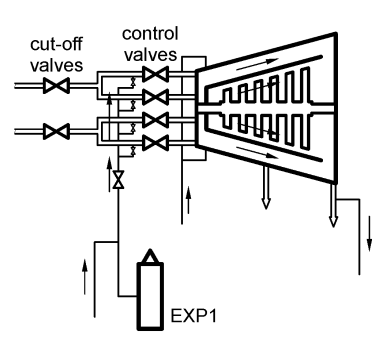

Fig. 7. Pre-heating with two separate flows

There are two flows in the turbine, one through the blades path and the other through the area between the casings. The flows may be adjusted separately. Even if the hot air is generated in an electric heater there is always a possibility to adjust each flow rate. The disadvantage here is that there are two entry points of the 
air into the cycle. They are shown in the fig. 7b. The exit point is just one for both streams as they mix in the rear end of the turbine.

In every configuration presented in this section the rotor must be running during the whole period of the preheating. It must be driven be an electric engine in order to prevent damage.

\section{Numerical modelling}

The pre-heating configurations were analysed against different conditions. The research involved numerical simulations of the thermal and the strength states of the main turbine parts. The rotor and the casings models were axisymmetric. Their shapes are shown in the fig. 8. The axisymmetric models are simplified especially for the casings. However the experience indicates that the stress in the rotor is al ways higher than in the casings. It is the rotor that determines the limits for the transient thermal states of the whole turbine. Therefore simplified models of the casings do not influence the limiting values of the stresses. The axisymmetric models of the casings provide practically the same results of the thermal elongations as the three dimensional versions.

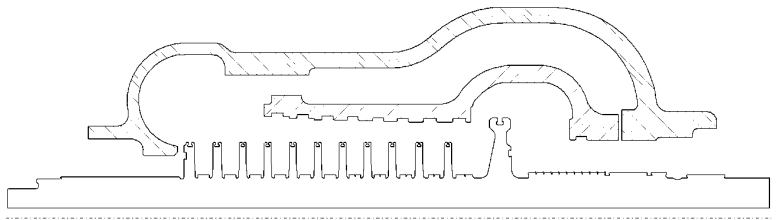

Fig. 8. M odels of the main turbine parts

The numerical calculations were conducted with the finite elements method that allowed to determine the distribution of the temperature, stress and displacements of the turbine parts. The most important displacement here are the elongations along the main axis of the turbine.

The surfaces of the parts were divided into sections that corresponded to similar boundary conditions. The convective heat transfer coefficients were calculated for each section from semi-empirical formulas [9-11].

\section{Analysis results}

The graphs in the following figures are a fraction of the whole research and are presented here to explain the investigated conditions of the pre-heating. Four cases (variants) were analysed and their symbols are given below.

- $\quad$ 1 - air delivered between the casings (fig. 5a).

- W2 - air delivered to the blades path (fig. 5b).

- W3 - air delivered between the casings and reversed in to the blades path (fig. 6).

- W 4 - two streams of the air (fig. 7).

The preliminary simulations allowed to narrow the values of the analysis parameters to a reasonable ranges. The primary criteria for the selection of the conditions were the stress level and the magnitude of the relative elongations between the casings and the rotor. The time of the pre-heating was between 180 and 240 minutes. The maximal air temperature was within the range of $350-400^{\circ} \mathrm{C}$. The air flow rate was kept constant.

There are several points of the stress concentration. The most important ones are shown in the fig. 9 together with their symbols.

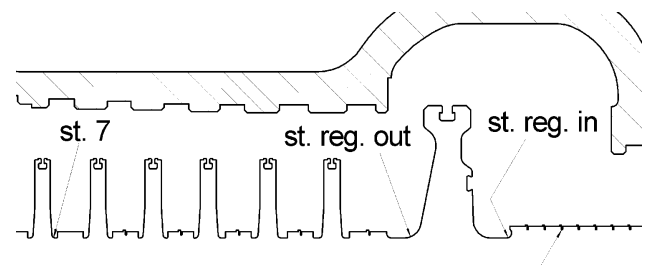

\section{st. reg. 0}

Fig. 9. Points of the stress concentration

Other symbols in the figures that show the numerical results include:

- $\quad$ inlet - front side of the turbine (steam inlet)

- KWW - high pressure inner casing,

- KZWP - high pressure outer casing,

- outlet - rear side of the turbine (steam outlet)

- $t$ - pre-heating time

- $\mathrm{T}$ - temperature in the blade path,

- $T_{m k}$ - temperature in the area between the inner and the outer casings.

- WW P - high pressure rotor.

The detailed graphs shown in the following five figure (figs. 10 - 14) correspond to the case number 2 with the period of the pre-heating lasting 210 minutes. The figures show the change of the chosen values over time.

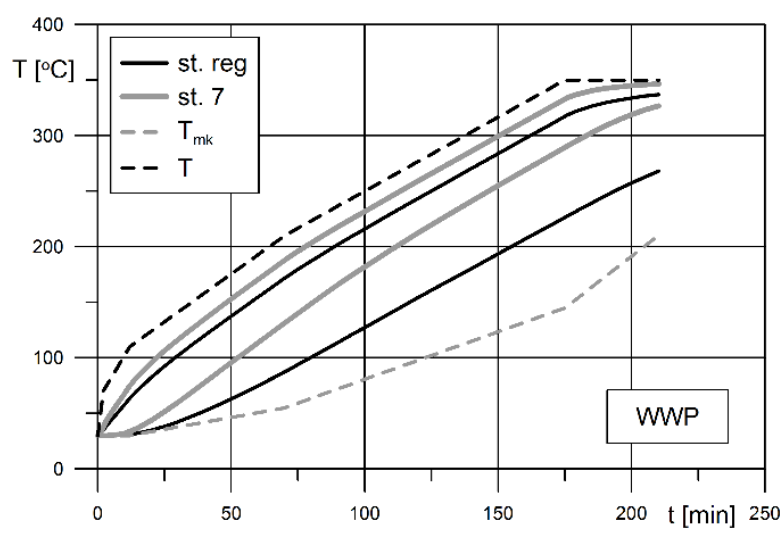

Fig. 10. Rotor temperature, case $W 2, t=210 \mathrm{~min}$

The graphs that show the temperature of the turbine parts include two lines of the same colour and type for the locations in the specific part. They refer to both sides of a part. The line that is located higher in the graph is related to the temperature on the surface that is exposed to the hot air. For example in the case number 1 the outer surface of the inner casing is exposed to the hot air. In the case number two it is the inner surface of the inner casing that is exposed to the hot flow. The line that is 
located lower is the temperature on the opposing side of the part not exposed to the flowing air.

The rotor is always exposed to the hot flow at its external surface. The second line in the graphs refers to the point located in the central void of the rotor in the same cross section as the point on the external surface.

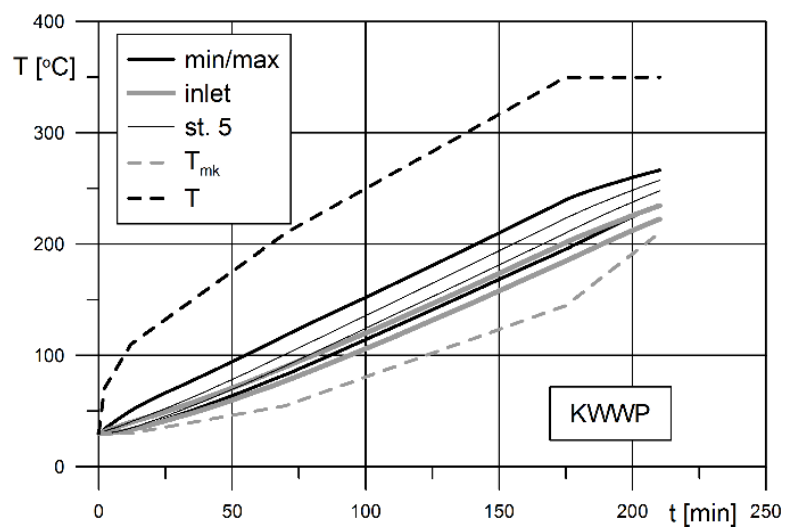

Fig. 11. Inner casing temperature, case $W 2, t=210 \mathrm{~min}$

The calculations of the relative elongations assume that the inner casing is attached to the outer casing in the cross-section where the live steam inlet is located. In the figures there are two symbols for two distinct relative elongations:

- WWP-KWWP - relative elongation between the rotor and the inner casing calculated in the outlet cross-section of the casing,

- WWP-KZWP - relative elongation between the rotor and the outer casing calculated in the rear end of the casing.

The second elongation from the above list is usually measured in most steam turbines.

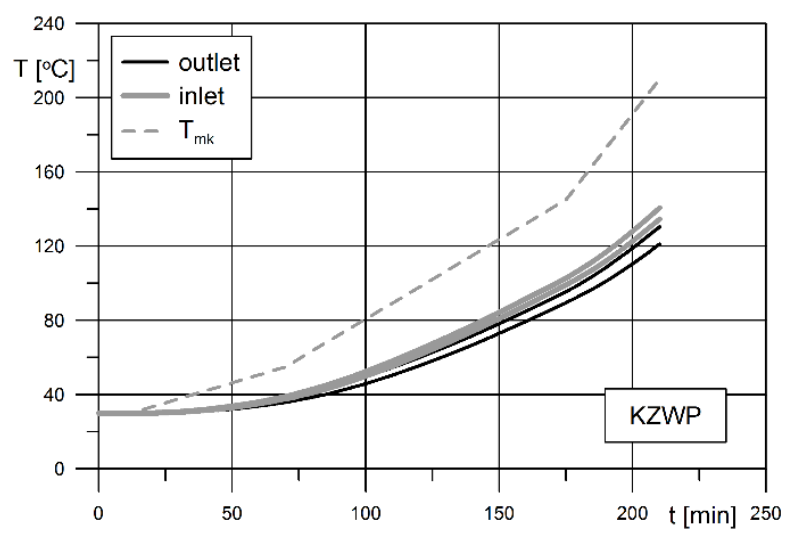

Fig. 12. O uter casing temperature, case $W 2, t=210 \mathrm{~min}$

In the cases 1 and 2 there is only one area filled with a flowing air. It is either the area between the casings or the blades path. The other one is filled with air, which does not flow. The heat transfer conditions there are similar to the natural convection. The exception is the surface of the is running rotor. Even if it is not exposed to the flowing air the convection is still intensive due to the rotational velocity.

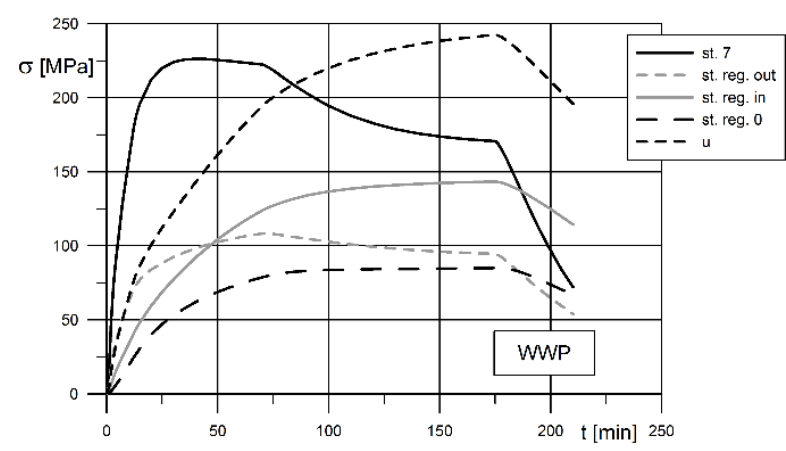

Fig. 13. Stress in the rotor, case $W 2, t=210 \mathrm{~min}$

It may be observed in the fig. 13 that the local maximal values of the stress occur in different moments in different sections of the rotor. This is the reason that five different characteristic locations are shown in order to fully present the change of the stress.

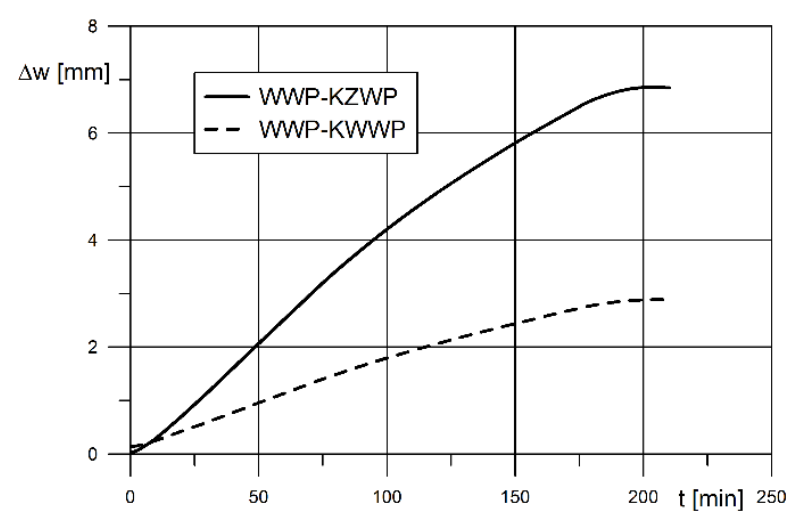

Fig. 14. Relative elongations, case $W 2, t=210 \mathrm{~min}$

The values of the elongations like the ones shown in fig. 14 must be confronted against the clearances set in the turbine in the axial direction.

\section{Comparison of the cases}

The result show that the most favourable thermal state in the turbine is achieved for the case number 4 of the air flow configuration.

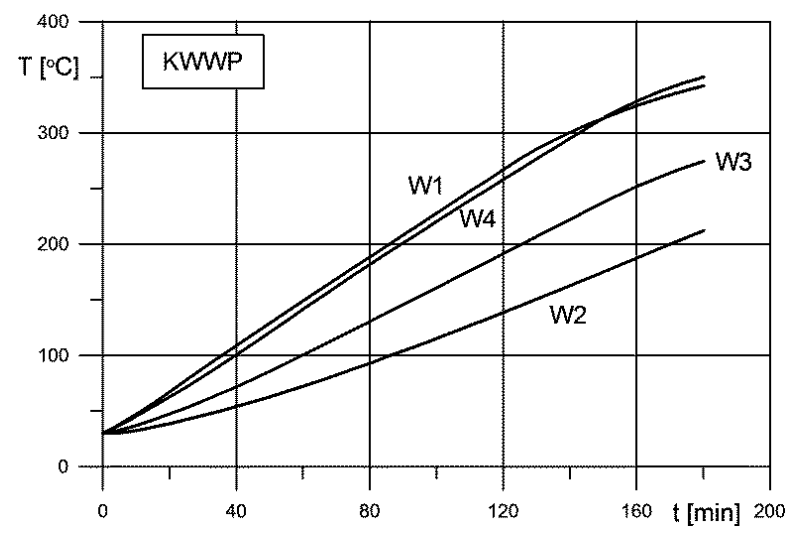

Fig. 15. Temperature of the inner casing 
If two streams of the hot air are delivered to the turbine then the temperature of the casings and the rotor increase simultaneously. At the end of the simulated period the inner casing and the rotor have the same temperature. This is clear when the lines for W 4 (case 4) are compared between the figures 15 and 16. The relative elongations are the smallest of all of the cases, which is visible in figs. 17 and 18 . This is because the temperature increase is the same in the casings and in the rotor.

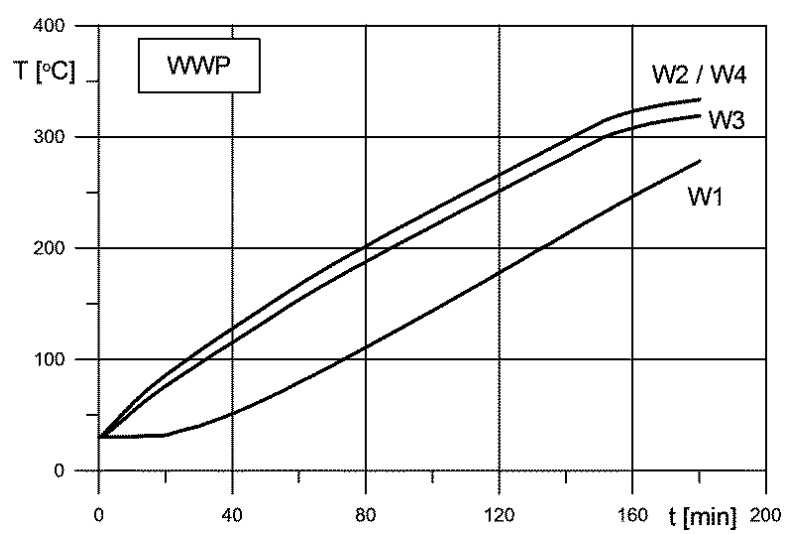

Fig. 16. Temperature of the rotor

Unfortunately the forth case causes some difficulties in the practical application. The heat source must deliver the air at two different temperature levels. In the simulations the maximal temperature between the casings was 50 degrees lower than the temperature in the blades path for the whole time of the pre-heating. It means that the electric air heater would require an air extraction.

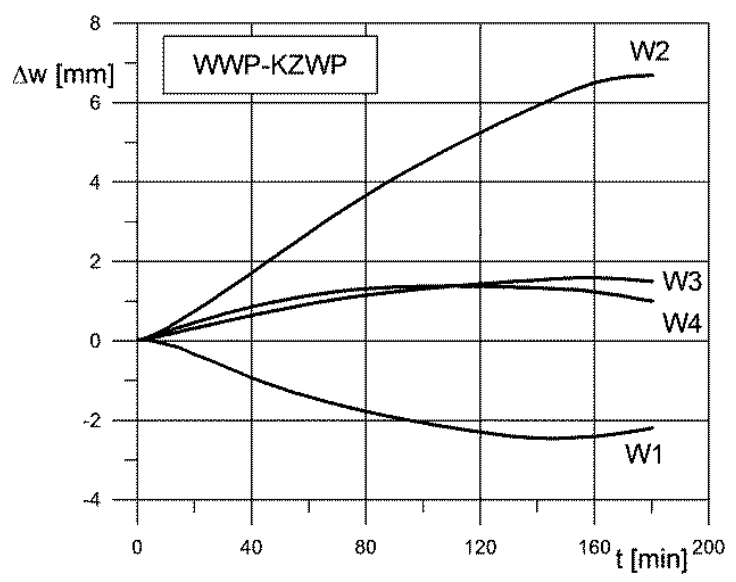

Fig. 17. Relative el ongations rotor - outer casing

A solution that is very close to the optimal case number 4 is the case number 3 , where the air flows between the casings and then in the blade path. The final temperature of the rotor at the end of the pre-heating is very close to the temperature of the rotor in the case 4, see fig. 16. The temperature of the inner casing is lower (fig. 15). This however is not a problem since the highest values of the stress occur in the rotor and not the casing.

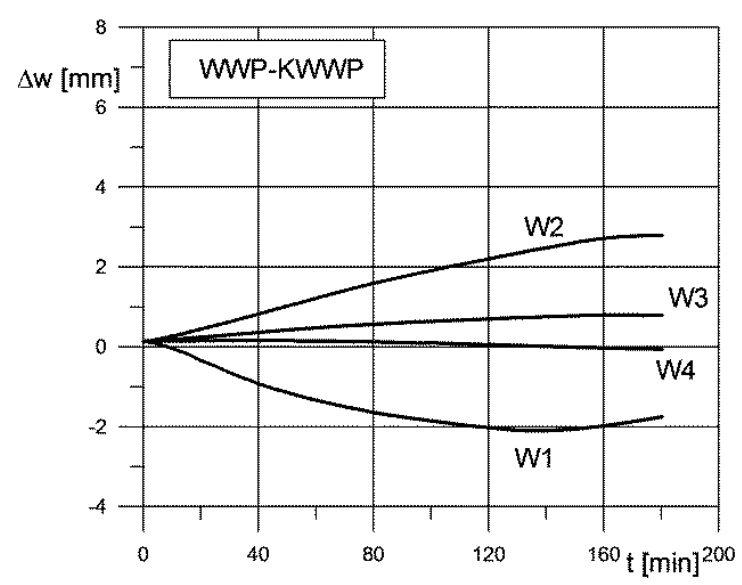

Fig. 18. Relative elongations rotor - inner casing

The case number 2 should be treated as an equivalent of the heating with a steam during a typical start-up. There are two differences. The first is that the preheating may begin earlier and that shortens the whole start-up. The second difference is the control of the process. It is much easier to control the flow and the temperature of the air than the steam that is generated in the boiler. Due to the size of the boiler its response is slower. The steam temperature may be decreased quite rapidly with the water injection but it cannot be raised so fast. The electric air heater allows much better flexibility in that regard.

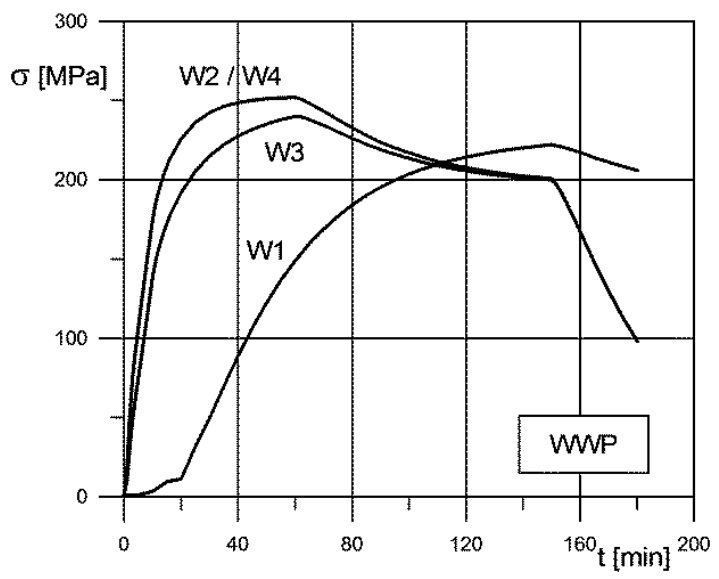

Fig. 19. Stress in the rotor for different flow cases

The pre-heating conducted according to the case number 1 results in negative relative elongations. Even though the absolute values are small they pose a threat of damage. The case number 1 is regarded here as an option for the control of the process. If the control valves are opened and closed accordingly the flow configuration changes between the cases number 1 and 3 . This allows to handle the thermal stress in a better way.

The comparison of the stress shown in the fig. 19 prove that the maximal level of the stress is quite similar for different cases. The graph in the figure was obtained for the groove near the disc of the seventh stage. The largest stress occurs for the air flow configurations when the rotor is directly exposed to the hot fluid. In the case number 3 the air that reaches the surface of the rotor has 
lower temperature than in other cases because it cools down in the area between the casings before entering the blade path.

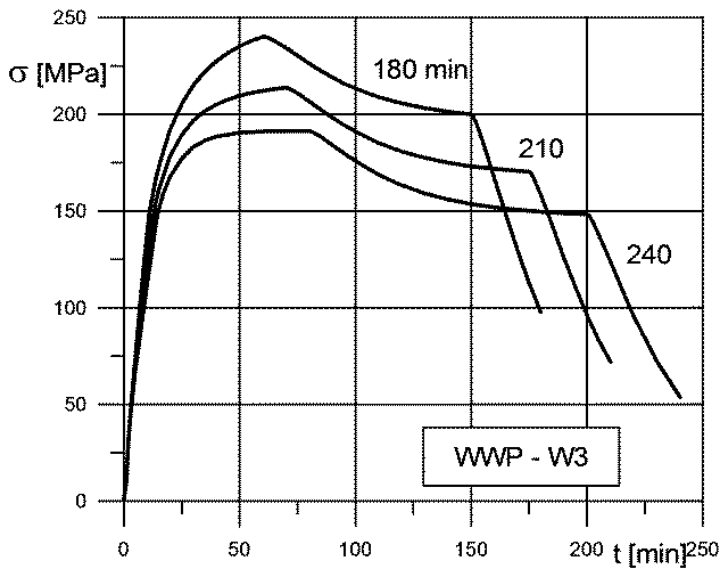

Fig. 20. Stress in the rotor for different length of the preheating period

In the case number 1 the maximal value of the stress is in the right side of the graph in the fig 19. This is a moment late in the process, when the air in the blades path finally reaches the temperature that results in the stress concentration in the rotor.

The basic time of the pre-heating process investigated in the simulations was 180 minutes. The stress in the rotor may be lowered if the period of the process is longer. The comparison of the stress in one point of the rotor for different length of the pre-heating is shown in fig. 20.

The maximal stress for the basic case is over $200 \mathrm{M} \mathrm{Pa}$. It should be noted that this is a local value that corresponds to a very small area of the rotor.

\section{Conclusions}

The analysis presented here indicates that the optimized procedure allows to conduct a start-up from a cold state much faster than the manufacturer's curves. The possible decrease of time derives from two modifications. Firstly an external heat source is used to increase the temperature of the parts of the turbine. This procedure may begin at the same time the boiler is started. Secondly the pre-heating raises the turbine temperature above the standard level. When the valves are open and the live steam is delivered to the turbine for the first time the turbine temperature is al ready quite high. The rate of the temperature increase may be higher.

The costs of the preheating system includes the electric air heater and the compressor. The latter may be omitted if a power plant has got an air collector pipe with the pressure at an appropriate level. This is usually the case if the force cooling is used after the shut-downs. The estimated cost of the electric heater is later covered by the reduced costs of the start-up.

The pre-heating procedure may be applied to the existing steam cycle. The key advantage of the presented method is the low number of the required modifications. The turbine itself is not modified at all. The system uses the existing pipes with one or two new inlets and outlets depending on the chosen air flow configuration.

References

1. Tumanovskii A.G., Shvarts A.L., Somova E.V., Verbovetskii E.K h., A vrutskii G.D., Ermakova S.V., Kalugin R.N., Lazarev M.V .: Review of the CoalFired, Over-Supercritical and UItra-Supercritical Steam Power Plants. Thermal Engineering, V ol. 64, No. 2, 2017, pp. 83-96.

2. Abe F.: Research and Development of HeatResistant $M$ aterials for A dvanced USC Power Plants with Steam Temperatures of $700 \mathrm{C}$ and Above. Engineering, 1(2), 2015, pp. 211-224.

3. Crespi F., Gavagnin G., Sanchez D., Martinez G.S.: Supercritical carbon dioxide cycles for power generation: A review. Applied Energy, Vol. 195, 2017, pp. 152-183.

4. Topel M., Guedez R., L aumert B .: Impact of increasing steam turbine flexibility on the annual performance of a direct steam generation tower power plant. „Energy Procedia” Vol. 69, 2015, pp. 1171-1180.

5. Chmielniak T.: Technologie energetyczne. Wydawnictwa Naukowo-Techniczne, Warszawa 2015.

6. Arkadyev B.A.: Features of Steam Turbine Cooling by the Example of an SKR-100 Turbine for Supercritical Steam Parameters. Thermal Engineering, V ol. 62, No. 10, 2015, pp. 728-734.

7. Zhao N., W ang W., Zhang J., Liu Y .: N umerical investigation on life improvement of low-cycle fatigue for an ultra-supercritical steam turbine rotor. „Journal of Mechanical Science and Technology”, Vol. 30 (4), 2016, pp. 1747-1754.

8. Rusin A., Łukowicz H., Lipka M.: Thermal states and stresses in selected structures of the supercritical and ultra-super critical turbines rotors. Journal of Power Technologies V ol. 96, Iss. 6, 2016, pp. 420431.

9. Bergman L. B., Lavine A. S., Incropera F. P., Dewitt D. P.: Fundamentals of Heat and Mass Transfer. W iley and Sons, 2011.

10. Dunn M.G.: Convective Heat Transfer and A erodynamics in Axial Flow Turbines. Journal of Turbomachinery, V ol. 123, pp. 637-686.

11. Lienhard IV J.H., Lienhard V J.H.: A Heat Transfer Textbook. Third Edition. Phlogiston Press, Cambrige, M assachusetts 2008. 